\title{
Long-term mortality after critical care: what is the starting point?
}

\author{
Otavio T Ranzani ${ }^{1 *}$, Fernando G Zampieri ${ }^{1,2}$, Marcelo Park ${ }^{1}$ and Jorge IF Salluh ${ }^{3}$ \\ See related research by Cuthbertson et al., http://ccforum.com/content/17/2/R70
}

\begin{abstract}
Mortality is still the most assessed outcome in the critically ill patient and is routinely used as the primary end-point in intervention trials, cohort studies, and benchmarking analysis. Despite this, interest in patient-centered prognosis after ICU discharge is increasing, and several studies report quality of life and long-term outcomes after critical illness. In a recent issue of Critical Care, Cuthbertson and colleagues reported interesting results from a cohort of 439 patients with sepsis, who showed high ongoing long-term mortality rates after severe sepsis, reaching $61 \%$ at 5 years (from a starting point of ICU admission). Follow-up may start at ICU admission, after ICU discharge, or after hospital discharge. Using ICU admission as a starting point will include patients with a wide range of illness severities and reasons for ICU admission. As a result, important consequences of the ICU, such as rehabilitation and reduced quality of life, may be diluted in an unselected population. ICU discharge is another frequently used starting point. ICU discharge is a marker of better outcome and reduced risk for acute deterioration, making this an interesting starting point for studying long-term mortality, need for ICU readmission, and critical illness rehabilitation. Finally, using hospital discharge as the starting point will include patients with the minimal requirements to sustain an adequate condition in a non-monitored environment but will add a 'survivors bias'; that is, patients who survive critical illness are a special group among the critically ill. In this commentary, we discuss the heterogeneity in long-term mortality from recent studies in critical care medicine - heterogeneity that may be a consequence simply of changing the follow-up starting point - and propose a standardized follow-up starting point for future studies according to the outcome of interest.
\end{abstract}

\section{Commentary}

Critical illness may occur at any time of life, having permanent effects not only on one's health but on other aspects of life, including spiritual, social, and familiar issues [1]. Despite this, mortality is still the most frequently assessed outcome in critically ill patients and is routinely used as the primary end-point in intervention trials, cohort studies, and benchmarking analysis $[2,3]$.

In recent years, the number of studies assessing survival and the overall medical condition of patients after ICU and hospital discharge has markedly increased [1]. However, there is still a need for additional sound data on reliable predictors of relevant, early and late, patientcentered outcomes [4]. In a recent issue of Critical Care,

\footnotetext{
* Correspondence: otavioranzani@yahoo.com.br

${ }^{1}$ Intensive Care Unit, Emergency Medicine Discipline, University of São Paulo, Rua Enéas Carvalho de Aguiar, 255, Sala 6040, Sexto Andar, São Paulo 05403-000, Brazil

Full list of author information is available at the end of the article
}

Cuthbertson and colleagues [1], using ICU admission as the starting point, reported an ongoing long-term mortality rate of $61 \%$ in patients with severe sepsis. Also using ICU admission as the starting point, Nesseler and colleagues [5] recently showed a long-term mortality of $45 \%$ among patients with septic shock. In contrast, Brinkman and colleagues [4] conducted a systematic review of long-term mortality of critically ill patients, whose data were drawn from 24 studies. The authors found that $24 \%$ of the patients died after hospital discharge. This number counterpoints the high mortality observed in the cited studies and highlights the importance of using the same starting point when comparing studies, as discussed by the authors [4].

To illustrate the importance of defining the follow-up starting point, we recovered data from recent trials and cohort studies of patients with sepsis and compared the reported mortality if starting point was changed. As depicted in Table 1, the difference of long-term mortality 
Table 1 Effect on long-term mortality rate of patients with sepsis if the starting point of follow-up is changed

\begin{tabular}{|c|c|c|c|c|c|}
\hline Study & Longer follow-up reported & Shorter follow-up reported & $\begin{array}{l}\text { Long-term mortality } \\
\text { changing the starting point }\end{array}$ & Difference & Reduction \\
\hline CATS [2] $(n=330)$ & $51.2 \%(169 / 330) 90$ days & $45.5 \%(150 / 330) I C U$ & $10.6 \%(19 / 180)$ & $40.6 \%$ & $79.3 \%$ \\
\hline Nesseler et al. [5] $(n=93)$ & $45.2 \%(42 / 93) 180$ days & $28 \%(26 / 93)$ ICU & $23.9 \%(16 / 67)$ & $21.3 \%$ & $47.1 \%$ \\
\hline Granja et al. [6] $(n=305)$ & $39.7 \%(121 / 305) 180$ days & $24.6 \%(75 / 305) I C U$ & $20.0 \%(46 / 230)$ & $19.7 \%$ & $49.6 \%$ \\
\hline Baudouin et al. [7] $(n=150)$ & 48.7\% (73/150) 180 days & $27.3 \%(41 / 150) I C U$ & $29.4 \%(32 / 109)$ & $19.3 \%$ & $39.6 \%$ \\
\hline Cuthbertson et al. [1] $(n=439)$ & $60.8 \%(267 / 439) 5$ years & $39.2 \%(172 / 439)$ ICU & $35.6 \%(95 / 267)$ & $25.2 \%$ & $41.4 \%$ \\
\hline Angus et al. [8] $(n=1,690)$ & $51.0 \% 2.5$ years & $27.8 \%(469 / 1,690) 28$ days & $32.2 \%$ & $18.8 \%$ & $36.9 \%$ \\
\hline VASST [3] $(n=778)$ & $46.7 \%$ (360/771) 90 days & $37.3 \%$ (290/778) 28 days & $14.3 \%(70 / 488)$ & $32.4 \%$ & $69.4 \%$ \\
\hline PROWESS-Shock $[9](n=1,697)$ & $33.4 \%(556 / 1,664) 90$ days & $25.3 \%(425 / 1,680) 28$ days & $10.4 \%(131 / 1,255)$ & $23.0 \%$ & $68.9 \%$ \\
\hline
\end{tabular}

CATS, Catecholamine study; PROWESS, Protein C worldwide evaluation in severe sepsis; VASST, Vasopressin versus norepinephrine infusion in patients with septic shock.

could reach $40.6 \%$ with data from the Catecholamine Study [2]. The 90 -day mortality was $51.2 \%$ if we chose ICU admission as the starting point; however, if we chose ICU discharge (that is, excluding patients who died in the ICU), the long-term mortality was $10.6 \%$. From the studies in Table 1, if the starting point followup is changed, the mean difference is $25.0 \%$ and the mean reduction in reported long-term mortality is $54.0 \%$. This analysis has the important limitation that, when the follow-up starting point is changed to ICU discharge, the total observation period will be less than 90 days; that is, it will be equal to 90 days minus the ICU length of stay.

We believe that, despite important advances in describing the natural history of ICU patients, it is crucial to better define our research questions. Indeed, recommendations provided directions to improve the research in this topic $[10,11]$, and standardization of some definitions and outcomes would result in studies that are more homogenous. First of all, what is the best starting point for the follow-up? Should follow-up start at ICU admission, after ICU discharge, or even after hospital discharge? Several studies have chosen ICU admission as the starting point. This definition, though practical, will include different strata of patients in regard to illness severity and reason for ICU admission, including a range of patients with scheduled ICU admission, which form a very distinct group. In fact, the first days of ICU admission are associated with higher risk of death and greatest vulnerability for the patient [10]. The first phase is followed by the recovery phase, which can be further complicated by secondary insults, especially hospital-acquired infections. Patients who had a secondary insult in the ICU are probably different than those who had a smooth course after admission and may not reflect the prognosis of all ICU survivors. ICU discharge can also be used as a starting point. At ICU discharge, residual organ failure and need for organ support are often reduced, as is the risk of deterioration. If this starting point is used, the risk of death is better balanced among critically ill patients, and this starting point is interesting for studying the role of important topics in long-term mortality, such as ICU readmission and critical illness rehabilitation [12]. Finally, using hospital discharge as the starting point will include patients who have the minimal requirements to sustain an adequate condition in a non-monitored environment and who therefore are more similar to patients who had no recent critical illness [13]. On the other hand, ICU survivors may represent patients with better previous health status (that is, patients who survived critical illness because of good previous health condition and status performance in other words 'survivor bias').

In conclusion, the current literature defines 'long-term mortality' for outcomes that are not limited to postdischarge mortality, resulting in a myriad of possible interpretations. The heterogeneity of case mix and other factors usually make for an intricate analysis, but different starting points play a central role in the differences between studies. For intervention trials and for benchmarking, the starting point should be either the ICU admission or syndrome/disease diagnosis. For attributable mortality, ICU admission instead of time of diagnosis would be better, as recently reported for ventilator-associated pneumonia [13]. ICU discharge is a remarkable starting point to identify high-risk patients who could receive beneficial close attention in the hospital and in outpatient clinics [14]. Depending on the quoted problem, each starting point can bring useful information. Therefore, to achieve better answers, we must know where, in the natural course of critical illness, our question lies.

\section{Competing interests}

The authors declare that they have no competing interests.

\section{Authors' contributions}

All authors equally contributed to the study.

\section{Author details}

${ }^{1}$ Intensive Care Unit, Emergency Medicine Discipline, University of São Paulo, Rua Enéas Carvalho de Aguiar, 255, Sala 6040, Sexto Andar, São Paulo 
05403-000, Brazil. ${ }^{2}$ Intensive Care Unit, Hospital Alemão Oswaldo Cruz, Rua João Julião 331, São Paulo 01323-020, Brazil. ${ }^{3}$ D'Or Institute for Research and Education, Rua Dinis Cordeiro 30, Rio de Janeiro 22281-100, Brazil.

Published: 27 Sep 2013

\section{References}

1. Cuthbertson BH, Elders A, Hall S, Taylor J, Maclennan G, McKirdy F, Mackenzie SJ: Scctg And Sics SC: Mortality and quality of life in the five years after severe sepsis. Crit Care 2013, 17:R70.

2. Annane D, Vignon P, Renault A, Bollaert PE, Charpentier C, Martin C, Troché G, Ricard JD, Nitenberg G, Papazian L, Azoulay E, Bellissant E, CATS Study Group: Norepinephrine plus dobutamine versus epinephrine alone for management of septic shock: a randomised trial. Lancet 2007, 370:676-684.

3. Russell JA, Walley KR, Singer J, Gordon AC, Hébert PC, Cooper DJ, Holmes CL, Mehta S, Granton JT, Storms MM, Cook DJ, Presneill JJ, Ayers D, VASST Investigators: Vasopressin versus norepinephrine infusion in patients with septic shock. N Engl J Med 2008, 358:877-887.

4. Brinkman S, Bakhshi-Raiez F, Abu-Hanna A, Jonge E, de Keizer NF: Determinants of mortality after hospital discharge in ICU patients: literature review and Dutch cohort study. Crit Care Med 2013, 41:1237-1251.

5. Nesseler N, Defontaine A, Launey $Y$, Morcet J, Mallédant $Y$, Seguin P: Long-term mortality and quality of life after septic shock: a follow-up observational study. Intensive Care Med 2013, 39:881-888.

6. Granja C, Dias C, Costa-Pereira A, Sarmento A: Quality of life of survivors from severe sepsis and septic shock may be similar to that of others who survive critical illness. Crit Care 2004, 8:R91-R98.

7. Baudouin SV, Saunders D, Tiangyou W, Elson JL, Poynter J, Pyle A, Keers S, Turnbull DM, Howell N, Chinnery PF: Mitochondrial DNA and survival after sepsis: a prospective study. Lancet 2005, 366:2118-2121.

8. Angus DC, Laterre PF, Helterbrand J, Ely EW, Ball DE, Garg R, Weissfeld LA, Bernard GR, PROWESS Investigators: The effect of drotrecogin alfa (activated) on long-term survival after severe sepsis. Crit Care Med 2004, 32:2199-2206.

9. Ranieri VM, Thompson BT, Barie PS, Dhainaut JF, Douglas IS, Finfer S, Gårdlund B, Marshall JC, Rhodes A, Artigas A, Payen D, Tenhunen J, Al-Khalidi HR, Thompson V, Janes J, Macias WL, Vangerow B, Williams MD, PROWESS-SHOCK Study Group: Drotrecogin alfa (activated) in adults with septic shock. N Engl J Med 2012, 366:2055-2064.

10. Angus DC, Carlet J: Participants BR: Surviving intensive care: a report from the, Brussels Roundtable. Intensive Care Med 2002, 2003:368-377.

11. Dowdy DW, Needham DM, Mendez-Tellez PA, Herridge MS, Pronovost PJ: Studying outcomes of intensive care unit survivors: the role of the cohort study. Intensive Care Med 2005, 31:914-921.

12. Ranzani OT, Prada LF, Zampieri FG, Battaini LC, Pinaffi JV, Setogute YC, Salluh JI, Povoa P, Forte DN, Azevedo LC, Park M: Failure to reduce C-reactive protein levels more than $25 \%$ in the last 24 hours before intensive care unit discharge predicts higher in-hospital mortality: a cohort study. J Crit Care 2012, 27:525.e529-525.e515.

13. Bekaert M, Timsit JF, Vansteelandt S, Depuydt P, Vésin A, Garrouste-Orgeas M, Decruyenaere J, Clec'h C, Azoulay E, Benoit D, Outcomerea Study Group: Attributable mortality of ventilator-associated pneumonia: a reappraisal using causal analysis. Am J Respir Crit Care Med 2011, 184:1133-1139.

14. Daly K, Beale R, Chang RW: Reduction in mortality after inappropriate early discharge from intensive care unit: logistic regression triage model. BMJ 2001, 322:1274-1276.

$10.1186 / \mathrm{cc} 13024$

Cite this article as: Ranzani et al.: Long-term mortality after critical care: what is the starting point? Critical Care 2013, 17:191 